\title{
Sensitivity Studies With a Sea Ice-Mixed Layer-Pycnocline Model in the Weddell Sea
}

\author{
W. B. OWENS \\ Woods Hole Oceanographic Institution, Woods Hole, Massachusetts
}

P. LEMKE ${ }^{1}$

Max-Planck-Institut für Meteorologie, Hamburg, Federal Republic of Germany

\begin{abstract}
The sensitivity of a dynamic-thermodynamic sea ice model coupled to a one-dimensional mixed layer-pycnocline model to variations of dynamic and thermodynamic model parameters is investigated. Furthermore, the modifications of the model results due to the inclusion of a prognostic snow cover and the implementation of simplified sea ice rheologies are investigated. In these comparisons special emphasis is placed upon the ice-ocean boundary conditions (buoyancy fluxes) and the mixed layer properties.
\end{abstract}

\section{REVIEW AND INTRODUCTION}

Sea ice covers a substantial part of the polar oceans. The average winter sea ice extent amounts to approximately 13 million $\mathrm{km}^{2}$ in the Arctic and 18 million $\mathrm{km}^{2}$ in the Antarctic. The configuration of sea ice and open water in polar regions and the seasonal production of sea ice significantly influence variations of the atmospheric and oceanic circulation patterns on all climatic time scales. Sea ice effectively modifies the radiation budget and the exchange of heat and momentum between ocean and atmosphere because of its high albedo and insulating behavior. This modification strongly affects the mixed layer dynamics. In those regions of the ocean where the stratification is rather weak, the cooling and the brine rejection during the sea ice formation lead to deep and bottom water formation, which influences the deep ocean circulation.

Because of the action of surface waves and tides the sea ice is broken into separate floes of variable size, with small floes (several meters) close to the ice edge and large floes (tens of kilometers) in the interior pack ice. These floes move under the influence of winds and ocean currents, thereby modifying the amount of open water between them.

The fraction of the ocean covered by sea ice (i.e., the sea ice compactness or concentration) and the sea ice thickness are determined by two kinds of processes: thermodynamic processes (freezing and melting) and dynamic processes (sea ice drift). Freezing and melting are affected by radiation and heat exchange with the atmosphere and the ocean, whereas the sea ice motion is dominated by air and water stress, Coriolis force, ocean tilt, and internal ice stress. The latter describes the response of the sea ice to deformation (rafting and ridging). Sea ice models therefore consist of balance equations for sea ice mass, compactness, and momentum.

Earlier simple sea ice models accounted only for the thermodynamic processes and neglected sea ice drift, as-

\footnotetext{
${ }^{1}$ Now at Alfred Wegener Institute for Polar and Marine Research, Bremerhaven, Federal Republic of Germany.

Copyright 1990 by the American Geophysical Union.

Paper number $90 \mathrm{JC} 00255$.

0148-0227/90/90JC-00255\$05.00
}

suming that advective effects are small on climatic temporal and spatial scales. The most sophisticated thermodynamic sea ice model was developed by Maykut and Untersteiner [1971]. In this model the heat conduction equation is numerically solved for a two-layer (snow and ice) system. The great complexity of this approach lies in the fact that the ice density, specific heat, and thermal conductivity are all functions of the sea ice salinity and temperature. These dependencies are caused by salt trapped in brine pockets that are in phase equilibrium with the surrounding ice. Because of this great complexity the model is difficult to use for climate purposes. A simplified version that retains the most essential components of this model was proposed by Semtner [1976]. An even simpler model was also proposed by Semtner [1976], in which a linear equilibrium temperature profile is assumed in both the ice and snow. The vertical heat conduction is uniform in both layers, and is proportional to the temperature gradient given by the temperature difference between the surface and the bottom of the ice and the thickness of both layers. The bottom temperature of the ice is specified by the freezing point of seawater $\left(\approx-2^{\circ} \mathrm{C}\right)$. The surface temperature is determined from a surface energy balance which includes latent and sensible heat fluxes, incoming solar and long-wave radiation, outgoing long-wave radiation, and heat conduction through the ice. If the surface temperature derived from this energy balance is above the melting point, the surface melting is determined from recomputing the energy balance with a surface temperature of $0^{\circ} \mathrm{C}$. The net energy available is then used to melt snow or ice. If the surface temperature is determined to be below freezing, the sea ice growth rate is given by the heat conduction through the ice reduced by the oceanic heat flux penetrating the bottom of the ice. This oceanic heat flux is usually taken to be constant and ranges between 2 and $20 \mathrm{~W} / \mathrm{m}^{2}$. This simple thermodynamic sea ice model is the one most commonly used in climate studies.

Washington et al. [1976] have applied Semtner's simple model to both polar regions using climatological atmospheric data and an oceanic heat flux of $2 \mathrm{~W} / \mathrm{m}^{2}$. The model results show that the Arctic sea ice extent is only slightly overestimated in winter and slightly underestimated in summer. The 
Antarctic results, however, are in poor agreement with observations. Ice extent and thickness are much too large. Washington et al. [1976] find that the inclusion of leads (open water within the pack ice) and an increase of the oceanic heat flux to $12 \mathrm{~W} / \mathrm{m}^{2}$ improve the model results. Although the magnitudes of the simulated sea ice thickness and extent for both polar regions are reasonable using the modified model, the geographical thickness pattern is not in good agreement with observations, especially in the Arctic. Thermodynamic models obtain the largest ice thickness near the pole, whereas observations show a greater buildup of ice near the Canadian Archipelago. The reason for this discrepancy is the omission of the sea ice motion in the ice mass balance.

Generally, growth and drift are equally important in the sea ice mass balance, and they are intrinsically related. The freezing rates in winter depend on the ice thickness, which in turn depends on the ice velocity pattern. The sea ice velocity, on the other hand, is modified by the distribution of thin and thick ice, because thin ice resists compression less than thick ice does.

Although the ice cover consists of a large number of separate floes of varying size, sea ice can be described to a good approximation as a two-dimensional continuum. The ice drift is then determined from a momentum balance, which consists of the acceleration term, the Coriolis force, the ocean tilt, the forces due to air and water stresses, and, finally, the internal ice force given by the divergence of the internal ice stress tensor [Rothrock, 1975a; Hibler, 1980a, 1986]. Existing sea ice models which include ice transport, differ mainly in the way the internal ice stress is treated. This includes modifications to both the parameters and form of the constitutive law relating the ice stress to ice deformation.

Drift models (no thermodynamics) have applied free drift (neglecting internal ice stress and acceleration, [Felzenbaum, 1958], or treated the sea ice as a viscous material [Campbell, 1965; Campbell and Rasmussen, 1972] or as an incompressible fluid [Rothrock, 1975b].

Seasonal transport models (including thermodynamics) which can be used for long-term climate simulations have been applied in three different ways. Bryan et al. [1975] have coupled a simple one-layer thermodynamic model to an atmospheric and oceanic circulation model. The snow cover in this model is incorporated as part of the ice. The sea ice motion is described by allowing the ice to drift with the upper layer of the ocean until it reaches a fixed cutoff thickness (4 m). At this thickness the sea ice motion is completely stopped.

Parkinson and Washington [1979] use the thermodynamic sea ice model of Washington et al. [1976] with climatologically averaged data, and include an ice transport based on a free drift momentum balance until the fraction of open water reaches a minimum value. Then the divergence rate is iteratively corrected to maintain a fixed minimum fraction of leads. The resulting sea ice drift is rather small compared to observations, and the resulting thickness distribution differs little from those obtained from purely thermodynamic models, with thicker ice near the poles.

The most sophisticated sea ice model is the one proposed by Hibler [1979]. This model includes a representation of thermodynamic processes similar to those of Parkinson and Washington [1979], and applies the momentum balance including the divergence of an internal ice stress tensor, in which the sea ice is treated as a viscous-plastic material. To allow the ice interaction to become stronger in regions of ice convergence and weaker in regions of ice divergence, the plastic yield strength in this model was taken to be proportional to the ice thickness and exponentially dependent on the fraction of open water. The ice mass and the ice concentration evolve according to continuity equations. In contrast to Parkinson and Washington [1979], ice convergence is allowed even for high concentrations. Convergence thickens the ice making it stronger and more resistant to further compression. The resulting fields of ice velocity and thickness demonstrate the improvement obtained with the viscous-plastic sea ice rheology. The agreement with observations is clearly better than in other models, especially the simulated ice buildup along the Canadian Archipelago, and the thinning of ice along the Siberian coast. This model was also applied to the Weddell Sea [Hibler and Ackley, 1983; Hibler, 1984; Lemke et al., this issue]. An extension of this two-level model to a multilevel version was given by Hibler [1980b].

In this paper the sensitivity of the sea ice-mixed layerpycnocline model described in detail by Lemke et al. [this issue] (hereinafter LOH) to the inclusion of a snow layer, to modifications of thermodynamic and dynamic parameters, and to the application of simplified sea ice rheologies will be investigated. The discussion includes variations of sea ice and mixed layer properties.

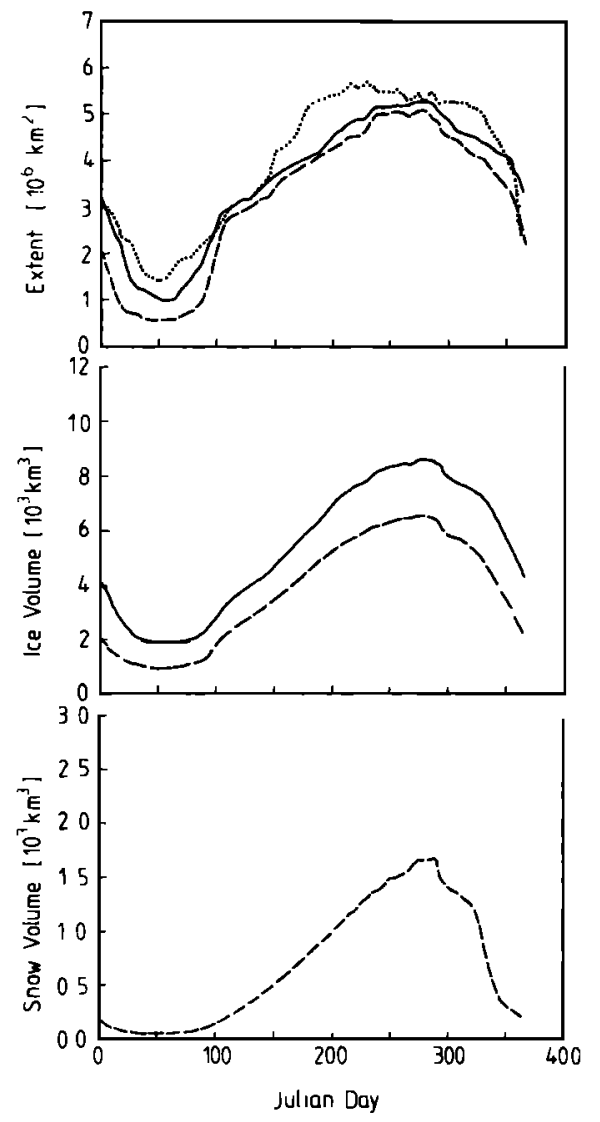

Fig. 1. Seasonal cycle of the integrated ice-covered area (upper panel), ice volume (middle panel), and snow volume (lower panel) for the experiment with (dashed lines) and without (solid lines) prognostic snow cover. Shown also is the observed integrated ice area (dotted line). 

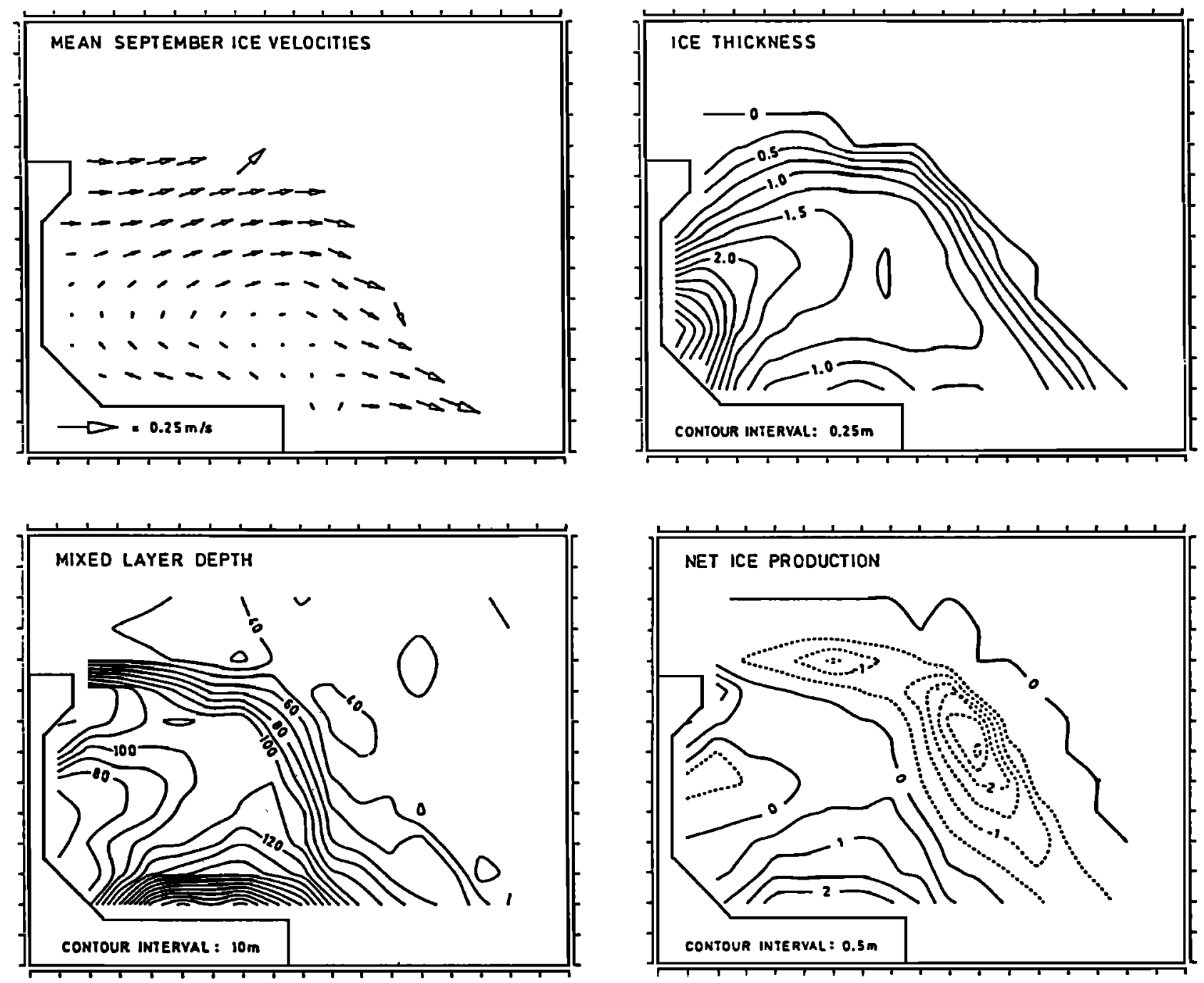

Fig. 2. Simulated mean September sea ice velocities, sea ice thickness and mixed layer depth on October 6, and annual net ice production in the Weddell Sea from the experiment with the prognostic snow cover.

In the next section, a short description of the coupled model is given. In the following section a series of model simulations demonstrates the sensitivity of the results to sea ice dynamics and snow cover.

\section{MOdel Description}

In this study a version of the two-layer dynamicthermodynamic sea ice model of the Weddell Sea [Hibler, 1984] is coupled to a one-dimensional, prognostic mixed layer similar to $\mathrm{LOH}$. In addition, the thermodynamics of the sea ice has been modified to include a snow layer as formulated by Semtner [1976] (see also Walsh et al. [1985]). Basically, the sea ice model consists of a momentum balance coupled to ice and snow thickness and compactness (fraction of area covered by sea ice) equations. In the latter equations the oceanic heat flux is determined by the mixed layer dynamics which also describes the depth, temperature, and salinity of the mixed layer and the pycnocline. Below we will give a brief description of the model to show the differences compared to LOH due to the inclusion of a snow layer.

For this study the momentum equation is unchanged from that in $\mathrm{LOH}$ :

$$
m D \mathbf{u} / D t=-m f \mathbf{k} \times \mathbf{u}+\tau_{a}+\tau_{w}-m g \nabla H+\mathbf{F}
$$

which includes inertial terms, Coriolis force, wind and water stresses, surface tilt, and internal ice interactions.

The internal ice forces can be written in terms of the divergence of the two-dimensional stress tensor, $\mathbf{F}=\boldsymbol{\nabla} \cdot \boldsymbol{\sigma}$. Following Hibler [1979], the ice is considered to have a nonlinear viscous-plastic constitutive law

$$
\sigma_{i j}=2 \eta\left(\dot{\varepsilon}_{i j}, P\right) \dot{\varepsilon}_{i j}+\left[\left(\zeta\left(\dot{\varepsilon}_{i j}, P\right)-\eta\left(\dot{\varepsilon}_{i j}, P\right)\right) \dot{\varepsilon}_{k k}-P / 2\right] \delta_{i j}
$$

where $\dot{\varepsilon}_{i j}$ is the strain rate tensor, $P / 2$ is a pressure term related to the ice thickness, $\dot{\varepsilon}_{k k}=\dot{\varepsilon}_{11}+\dot{\varepsilon}_{22}$ is the ice divergence, and $\zeta$ and $\eta$ are the nonlinear bulk and shear viscosities, respectively. The viscous-plastic constitutive law [Hibler, 1979] prescribes

$$
\zeta=P / 2 \Delta \quad \eta=\zeta / e^{2}
$$

where

$$
\Delta=\left[\left(\dot{\varepsilon}_{11}^{2}+\dot{\varepsilon}_{22}^{2}\right)\left(1+1 / e^{2}\right)+4 \dot{\varepsilon}_{12}^{2} / e^{2}+2 \dot{\varepsilon}_{11} \dot{\varepsilon}_{22}\left(1-1 / e^{2}\right)\right]^{1 / 2}
$$




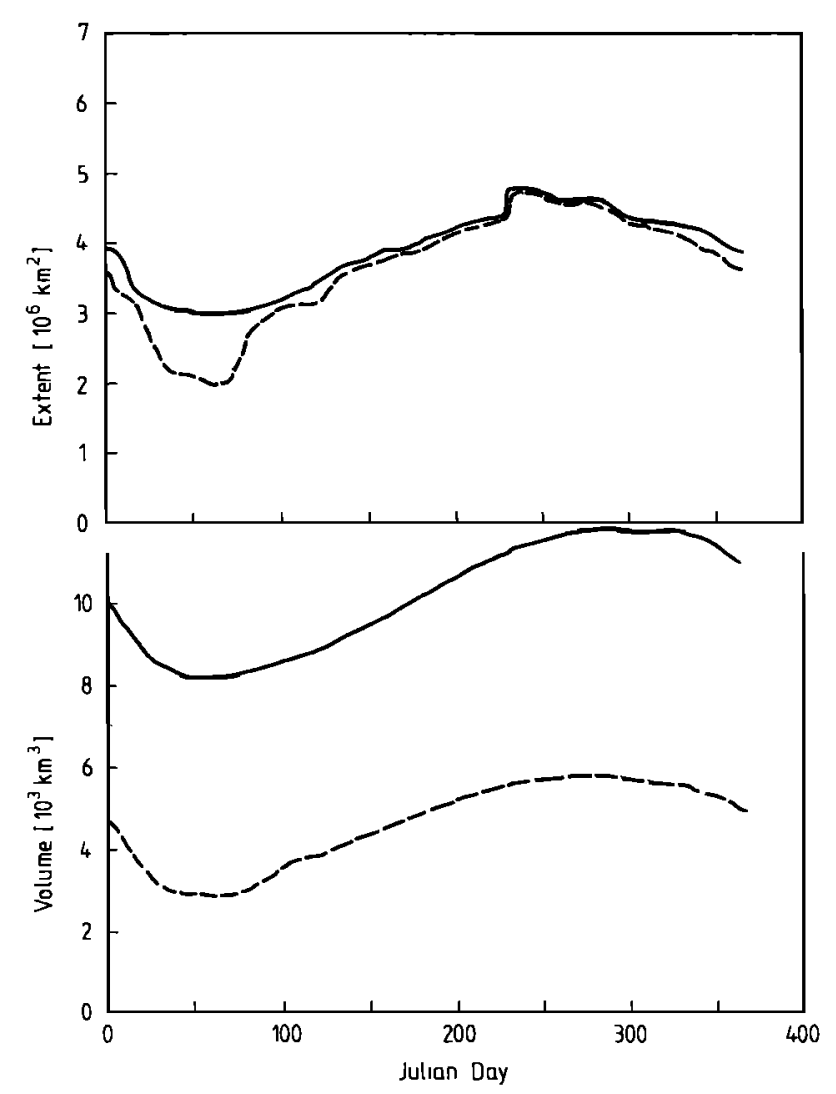

Fig. 3. Seasonal cycle of the integrated ice-covered area (upper panel) and ice volume (lower panel) for the thermodynamics-only experiment with (dashed lines) and without (solid lines) prognostic snow cover.

and $e$ is the ratio of the principal axes (eccentricity) of the elliptical yield curve. The viscosities are confined to finite values as the strain rates become small by limiting their values to be less than

$$
\zeta_{\max }=\left(2.5 \times 10^{8} s\right) P \quad \eta_{\max }=\zeta_{\max } / e^{2}
$$

The ice strength is coupled to ice thickness characteristics according to

$$
P=P^{*} h_{i} \exp [-C(1-A)]
$$

where $h_{i}$ is the areal average ice thickness and $A$ is the ice compactness or fraction of the area covered by ice.

In this formulation there are three model parameters that must be specified a priori, the ratio of principal axes, $e$, and the yield strength parameters $P^{*}$ and $C$. For this study the standard experiment (described in $\mathrm{LOH}$ ) uses the same values as Hibler and Ackley [1983], $e=2, P^{*}=2.75 \times 10^{4}$ $\mathrm{N} / \mathrm{m}^{2}$, and $C=20$. The sensitivity of the model results to variations of these three parameters will be investigated in section 3.

Local changes in ice thickness, compactness, and snow thickness, $h_{s}$, are computed from continuity equations for these variables:

$$
\begin{gathered}
\dot{h}_{i}=-\nabla \cdot\left(\mathbf{u} h_{i}\right)+S_{h}+\text { diffusion } \\
\dot{A}=-\nabla \cdot(\mathbf{u} A)+S_{A}+\text { diffusion }+S_{o p} \\
\dot{h}_{s}=-\nabla \cdot\left(\mathbf{u} h_{s}\right)+S_{s}+\text { diffusion }
\end{gathered}
$$

where $A \leq 1$. The first term on the right-hand sides represents the flux divergences into each grid cell. The ice velocities, calculated from the momentum equations, can be convergent due to either low ice strength (thin ice or small compactness) or pressure ridging when the ice deformations are large. As a result, one can obtain substantial flux divergences in regions with large gradients of ice thickness, compactness, or snow thickness. The diffusion terms are small and introduced solely for numerical purposes. $S_{o p}$ is a term representing the creation of open water by shear deformation [Hibler, 1984]. $S_{h}, S_{A}$, and $S_{s}$ are thermodynamic growth terms given by

$$
\begin{array}{cc}
S_{h}=A f\left(h_{i}^{*} / A\right) \Theta+(1-A) f(0)-Q_{o} /\left(\rho_{i} L\right) \\
S_{A}=(1-A) f(0) / h_{0}+x & f(0)>0 \\
S_{A}=0+x & f(0)<0
\end{array}
$$

where

$$
\begin{array}{ll}
x=0 & S_{h}>0 \\
x=\left(A / 2 h_{i}\right) S_{h} & S_{h}<0
\end{array}
$$
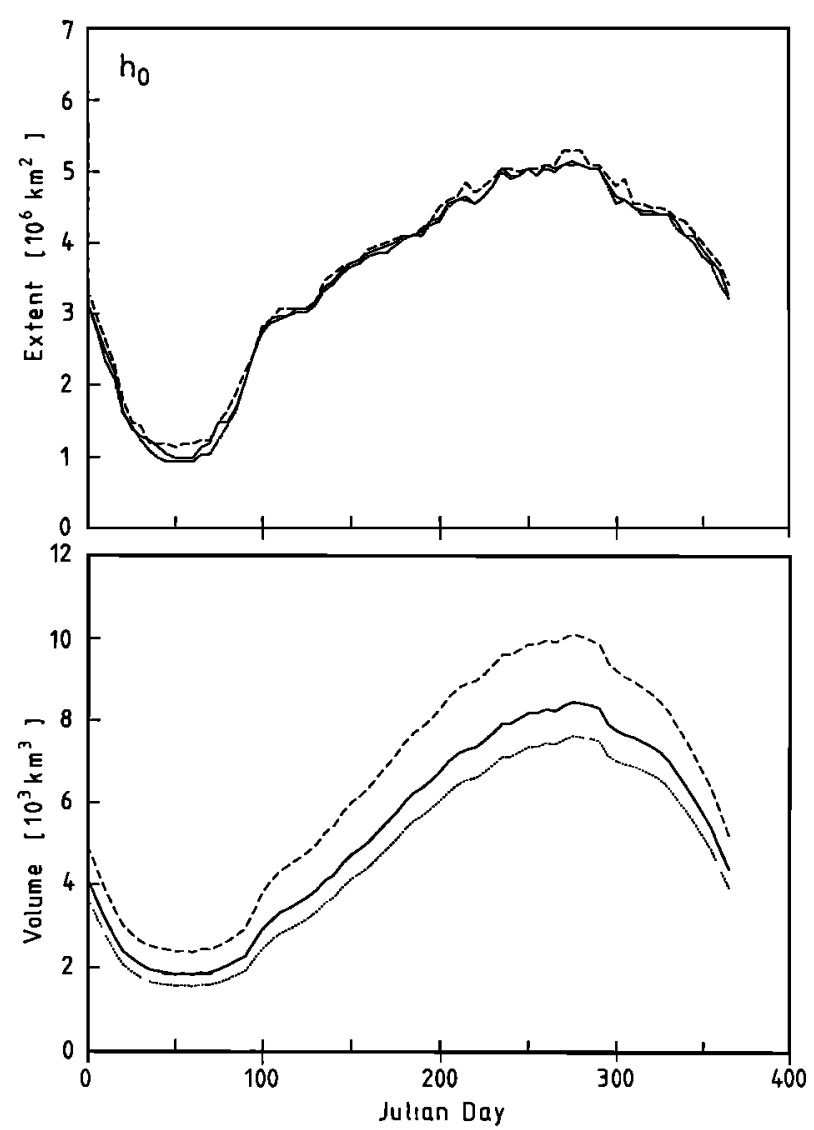

Fig. 4. Seasonal cycle of the integrated ice-covered area (upper panel) and ice volume (lower panel) for simulations with different values of the lead closing parameter (dashed lines, $h_{0}=1.0$; dotted lines, $h_{0}=0.3$ ). The standard experiment (solid lines) employs $h_{0}=$ 0.5 . 


$$
\begin{array}{ll}
S_{s}=A P_{w} \rho_{w} / \rho_{s}+y & T_{a} \leq 0^{\circ} \mathrm{C} \\
S_{s}=0+y & T_{a} \geq 0^{\circ} \mathrm{C}
\end{array}
$$

where

$$
\begin{array}{ll}
y=A f\left(h_{i}^{*} / A\right) \rho_{i} / \rho_{s} & f\left(h_{i}^{* / A} A\right)<0, h_{s}>0 \\
y=0 & \text { otherwise }
\end{array}
$$

with

$$
\begin{aligned}
& \Theta=0 \quad f\left(h_{i}^{*} / A\right)<0, \quad h_{s}>0 \\
& \Theta=1 \quad \text { otherwise }
\end{aligned}
$$

where $f(h)$ is the growth rate for ice of thickness $h$. The growth rates are determined from conductive heat fluxes through the ice which arise from conservation of energy at the upper surface of the snow/ice system [Semtner, 1976; Parkinson and Washington, 1979]. The $S_{h}$ term is the sum of the ice growth over both open water and that part of the grid cell covered by ice. Since the growth rate, $f(h)$, is a highly nonlinear function of ice thickness and, in reality, each cell is covered by a distribution of ice thicknesses which give the average thickness, $h_{i}$, we have followed the procedure of Hibler [1984] and estimated the growth rates $f(h)$ from an

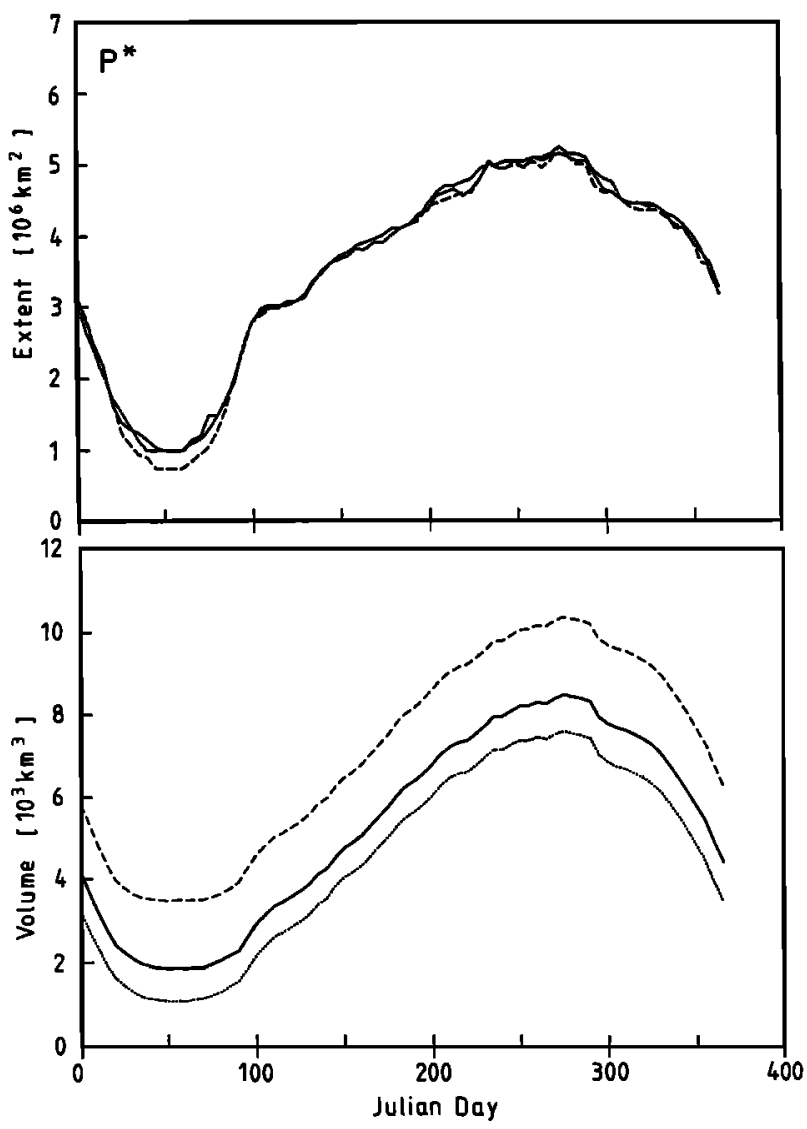

Fig. 5. Seasonal cycle of the integrated ice-covered area (upper panel) and ice volume (lower panel) for simulations with different values of the strength parameter $P^{*}$ (dashed lines, weak ice: $P^{*}=$ $5 \times 10^{3} \mathrm{~N} / \mathrm{m}^{2}$; dotted lines, strong ice: $P^{*}=10^{5} \mathrm{~N} / \mathrm{m}^{2}$ ). The standard experiment (solid lines) uses $P^{*}=2.75 \times 10^{4} \mathrm{~N} / \mathrm{m}^{2}$. equal, seven-level distribution between zero and twice the average thickness.

The inclusion of a snow layer modifies the calculation of the growth rates of ice, $f(h)$. Following Semtner [1976] and Parkinson and Washington [1979] we assume linear temperature gradients through the snow and ice layers and no internal heat sinks in either layer. In this case the conductive heat fluxes through the two layers must be the same, $Q_{i}=$ $Q_{s}$, and one can obtain the following:

$$
Q_{i}=Q_{s}=K_{i}\left(T_{f}-T_{s}\right) /\left[h_{i}+\left(K_{i} / K_{s}\right) h_{s}\right]
$$

where $K_{i}$ and $K_{s}$ are the thermal conductivities of ice and snow, respectively, and $T_{s}$ and $T_{f}$ are the temperatures at the top of the snow or ice layer and at the interface between the ice and water, respectively. It can be seen in this equation that in computing the ice growth rate one need only replace the ice thickness, $h_{i}$, with $h_{i}^{*}=h_{i}+\left(K_{i} / K_{s}\right) h_{s}$ and substitute a higher surface albedo ( 0.85 compared to 0.75 for frozen ice and 0.66 for melting ice) if a snow layer is present. Under atmospheric melting conditions, it is assumed that the snow is completely melted before any melting of ice begins. This is taken care of by $\Theta$ in (9). $Q_{o}$ in (9) denotes the vertical oceanic (entrainment) heat flux which is determined from the mixed layer model, and $\rho_{i}$ and $L$ are the density of sea ice and the latent heat of fusion, respectively.

The $S_{A}$ term characterizes how the growth rates of thick and thin ice affect the areal fraction of ice coverage. The first term in (10) parameterizes the closing of leads and open water under freezing conditions. It is assumed that the open water is not instantly covered by ice, but rather that the fraction of open water decays exponentially at a rate of $h_{0} / f(0)$. For example, in the Antarctic, frazil ice formation, followed by strong wind events redeposits thin ice under the ice floes [Ackley et al., 1980] which tends to slow the closing of open water. Nevertheless, although $h_{0}$ has a physical basis, and we estimate that this decay rate is of the order of 5 days, the exact value of $h_{0}$ is not known and is an important model parameter. For this study a standard value of $0.5 \mathrm{~m}$ has been used. Sensitivity experiments with different values will be presented in section 3 .

The second term $(x)$ in (10) accounts for the decrease in the fraction of the area covered by ice due to the melting of thick ice, assuming its thickness is distributed between 0 and twice $h_{i} / A$ and all the ice melts at the same rate.

For the $S_{s}$ term in (11) we have assumed a uniform precipitation rate of $\boldsymbol{P}_{w}=0.35 \mathrm{~m}$ of water per year. When the atmospheric temperature, $T_{a}$, is below freezing, this precipitation is in the form of snow (weighted with the ice concentration $A$ ); otherwise it is rain which we assume runs off through the leads and enters the oceanic mixed layer. The second term $(y)$ in (11) accounts for the melting of snow, and $\rho_{w}$ and $\rho_{s}$ denote the densities of seawater and snow, respectively.

Most aspects of the one-dimensional mixed layerpycnocline model are taken from LOH except for the freshwater flux, $F$, in (25) of $\mathrm{LOH}$ which is now determined by the precipitation $P_{w}$ and the melting of snow:

$$
\begin{array}{ll}
F=P_{w}(1-A)+z & T_{a} \leq 0 \\
F=P_{w}+z & T_{a}>0
\end{array}
$$

where 

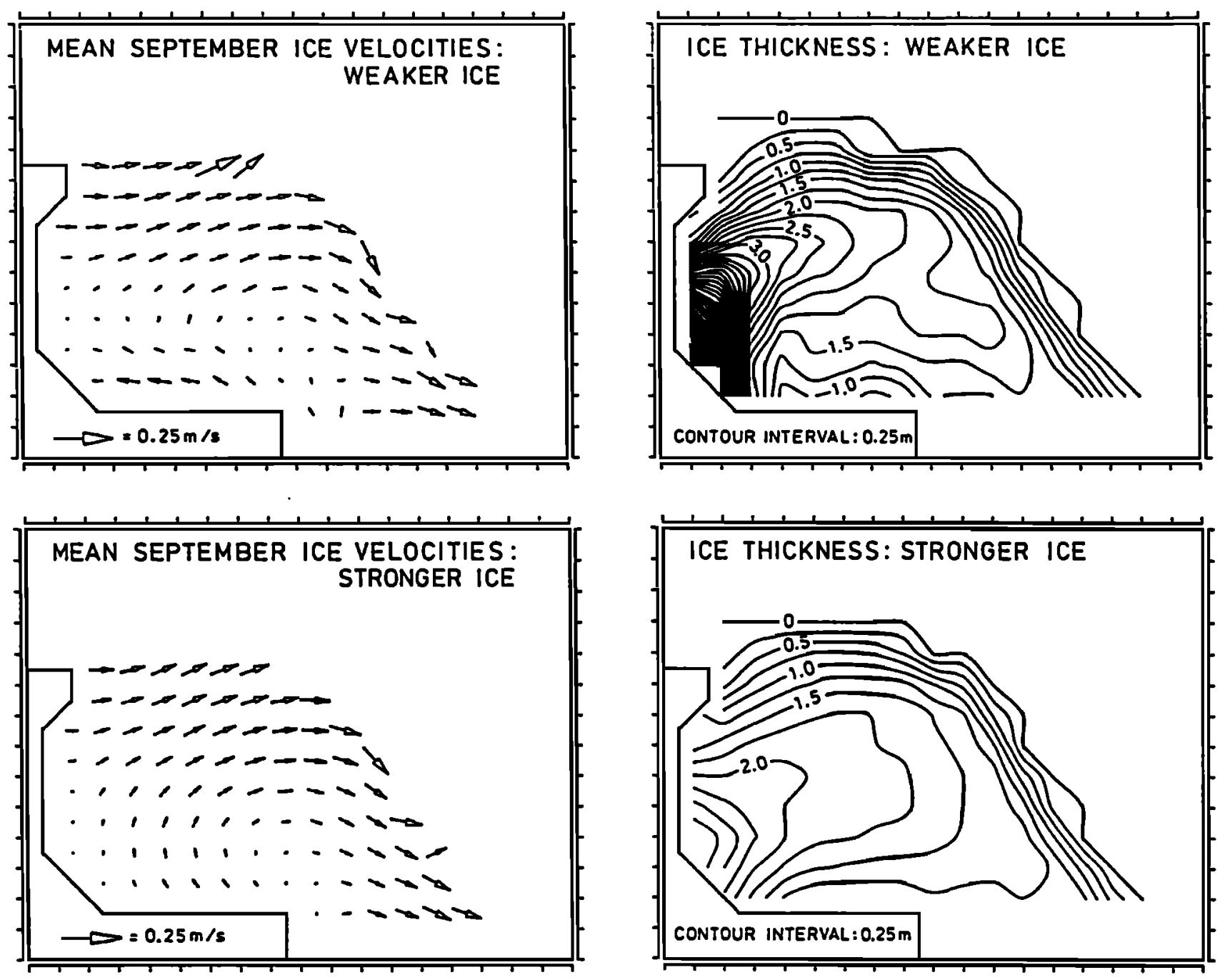

Fig. 6. Simulated mean September sea ice velocities and sea ice thicknesses on October 6 for the experiments with the smaller (upper panels) and the larger (lower panels) ice strength.

$$
\begin{array}{lll}
z=A f\left(h_{i}^{*} / A\right) \rho_{i} / \rho_{w} & f\left(h_{i}^{*} / A\right)<0 & h_{s}>0 \\
z=0 & \text { otherwise } &
\end{array}
$$

The model domain and integration procedure are the same as in $\mathrm{LOH}$.

\section{MODEL EXPERIMENTS}

A set of simulations has been performed to investigate the sensitivity of the ice-ocean model to the inclusion of a snow layer, to variations of thermodynamic and dynamic model parameters, and to different simplified rheologies. We will focus on the changes of ice extent, ice volume, net freezing rate, vertical oceanic heat flux, and other mixed layer variables. These model experiments will all be compared with the standard run described in detail in $\mathrm{LOH}$, which includes a prognostic mixed layer but no snow cover.

\subsection{Influence of Snow Cover}

A snow layer modifies the freezing rate of sea ice in two competing ways; it insulates the ice because of its low heat conductivity which reduces the heat loss to the atmosphere in winter, and its high albedo decreases the absorbed solar radiation. The first process decreases and the second increases the freezing rate of sea ice.

The seasonal response of the dynamic sea ice model with (dashed lines) and without (solid lines) a snow layer is presented in Figure 1. The seasonal phases of extent (upper panel) and volume (middle panel) are not modified by the snow cover. The extent is reduced slightly in winter and substantially in summer as compared to the standard run and to observations (dotted line). This can be explained by the strong reduction of the ice volume which amounts to $25 \%$ in winter and $50 \%$ in summer. Due to its good insulation the snow cover affects the ice thickness (volume) more than the extent. From this experiment it is obvious that the insulation effect on the freezing rates dominates the influence of the albedo. The snow volume is also shown in Figure 1 (lower panel).

The strong modification of our model results due to the prognostic snow cover is in contrast to conclusions from Maykut and Untersteiner [1971]. This discrepancy can be explained by the fact that Maykut and Untersteiner [1971] investigated snow on thick, multiyear ice where $h_{i}^{*}$ is only slightly larger than $h_{i}$, i.e., the snow thickness is relatively small compared to the ice thickness. For seasonal (thin) ice 
the snow thickness is comparable to the ice thickness and hence $h_{i}^{*}$ is substantially larger than $h_{i}$. This leads to the pronounced decrease of the freezing rate.

It should also be noted that the parameters of the sea ice model were tuned to fit the model results to observations without using prognostic models for the oceanic mixed layer and the snow cover [Hibler and Ackley, 1983]. These parameter values (also used in our standard and snow experiments) are not necessarily the optimal ones for the extended snowsea ice-mixed layer-pycnocline model. Although a modification of the model parameters would improve the results of the snow experiment, we think that the parameter adjustment should be carried out with an enclosed ocean circulation model. This will be the topic of a subsequent paper.

Figure 2 displays the geographical distributions of the model variables from the snow experiment. The sea ice velocity is not modified by the presence of the snow cover as compared to the standard run. The ice thickness, on the other hand, is reduced by $25 \%$. The simulated ice thicknesses in the eastern Weddell Sea are in better agreement with the observations taken by Wadhams et al. [1987] than those obtained from the standard run. The mixed layer depth differs only slightly from the standard experiment. The average oceanic heat flux under the ice is reduced from 3.26 $\mathrm{W} / \mathrm{m}^{2}$ to $2.84 \mathrm{~W} / \mathrm{m}^{2}$ (not shown). The amplitude of the net freezing rate decreased by $0.8 \mathrm{~m} / \mathrm{yr}(25 \%)$. Since the net
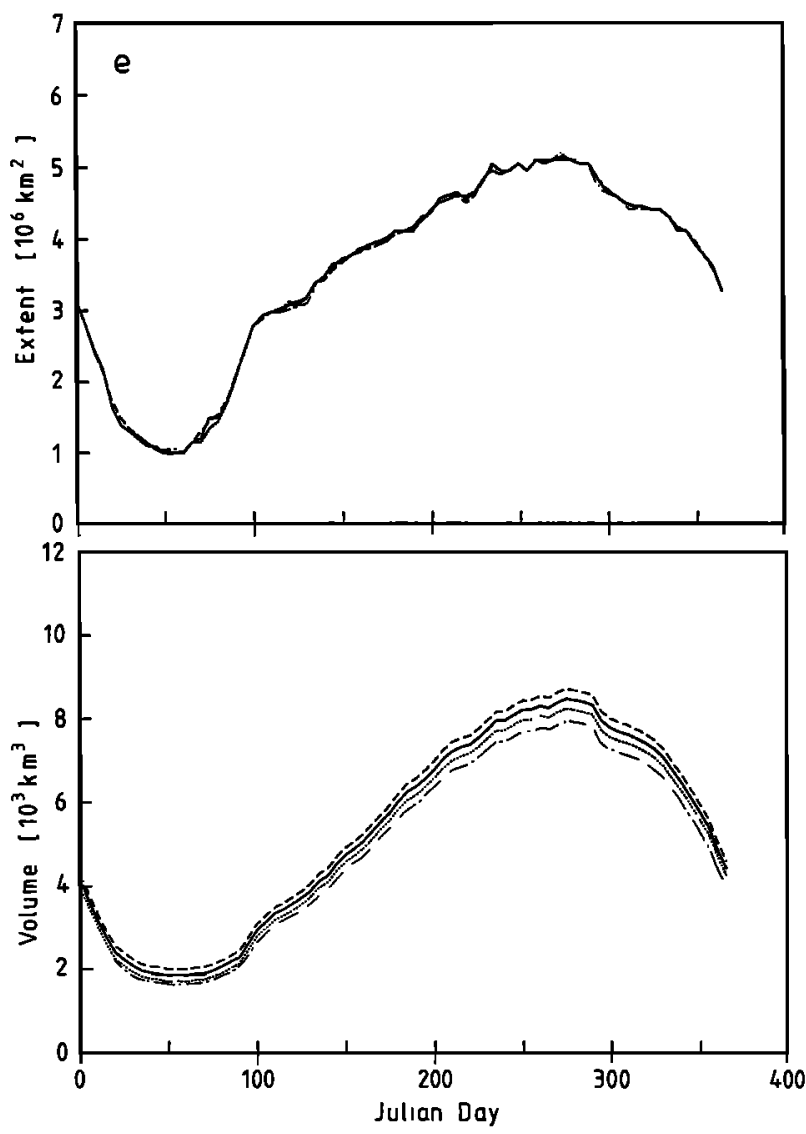

Fig. 7. Seasonal cycle of the integrated ice-covered area (upper panel) and ice volume (lower panel) for simulations with different values of the ratio of bulk to shear viscosity (dashed lines: $e=1.5$ dotted lines: $e=3$; dashed-dotted lines: $e=10$ ). The standard experiment (solid lines) employs $e=2$.
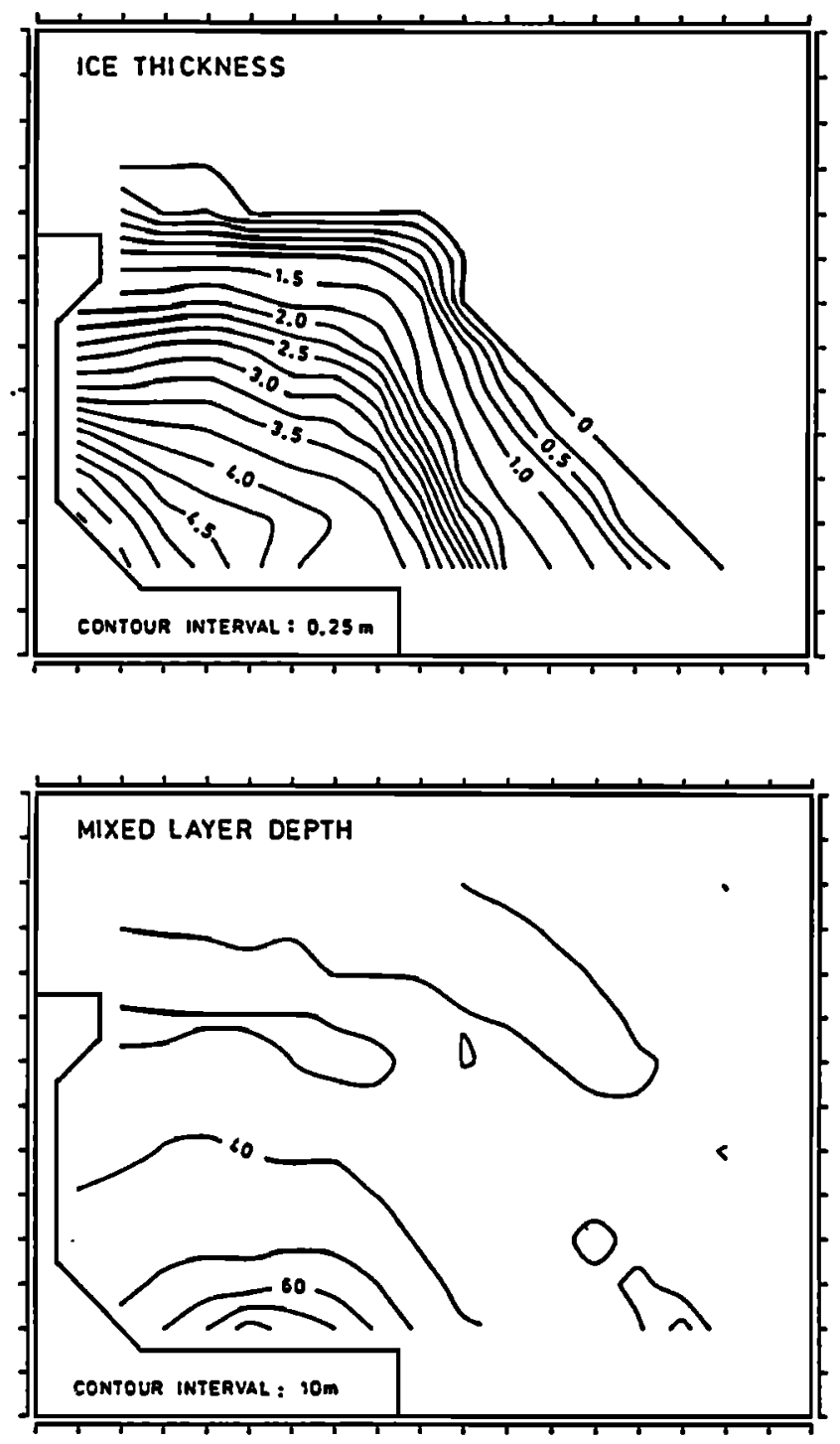

Fig. 8. Sea ice thickness and mixed layer depth on October 6 for the thermodynamic sea ice model (no advection).

freezing rate controls the mixed layer salt content, the salinity gradients are similarly reduced, while retaining the same pattern as the standard run.

In order to investigate the sensitivity of the dynamic sea ice model to snow cover effects relative to a thermodynamic model, in our next experiment the velocity of the ice-snow model was set to zero. The results of this run together with the results of a thermodynamic only experiment without snow cover (see $\mathrm{LOH}$ and section 3.3) are displayed in Figure 3. The snow reduces the summer ice extent considerably, whereas the winter extent remains similar. The sea ice volume is reduced drastically (more than 50\%). Comparing these results with Figure 1 it is obvious that the snow cover affects the thermodynamic sea ice model more than the dynamic model. Similar to the results of the LOH paper the dynamic sea ice model shows a reduced sensitivity compared to a simple thermodynamic model.

This feature can be explained by the specific interaction between the dynamics and the thermodynamics of the sea ice model. In regions where the thermodynamics reduces the ice thickness, the ice gets weaker and the dynamics (under 
favorable conditions, i.e., convergence) can readily increase the ice thickness (by importing ice into the region). In regions where the dynamics reduces the ice thickness (divergence), the thermodynamics (under favorable conditions, i.e., cooling) can easily increase the sea ice thickness. These interactions produce a negative, i.e., stabilizing feedback.

\subsection{Sensitivity to Model Parameters}

The remaining experiments discussed in this paper use the model version without the snow cover description.

3.2.1. The lead closing rate parameter $h_{0}$. The results of two experiments performed to investigate the sensitivity of the model to changes of $h_{0}$ are presented in Figure 4. From (10), $h_{0}$ is a model parameter which determines the time scale of the closing of leads and open water under freezing conditions. The standard run (solid line) used a value of $h_{0}=$ $0.5 \mathrm{~m}$ and the sensitivity experiments employed $h_{0}=1.0 \mathrm{~m}$ and $h_{0}=0.3 \mathrm{~m}$. The seasonal cycles indicate only a slight increase of the extent for larger $h_{0}$ (slower closing rate) and a slight decrease for smaller $h_{0}$ (larger closing rate). The volume, on the other hand, shows a pronounced (20\%) enhancement for $h_{0}=1.0 \mathrm{~m}$, and a decrease (10\%) for $h_{0}=$ $0.3 \mathrm{~m}$.

The sea ice velocity shows only minor differences between the three experiments. The ice thickness is increased by 0.25 $\mathrm{m}$ for $h_{0}=1.0 \mathrm{~m}$ and is reduced slightly for $h_{0}=0.3 \mathrm{~m}$, whereas the patterns remain similar. The mixed layer depth is slightly deeper for larger $h_{0}$ and slightly shallower for smaller $h_{0}$. The average oceanic heat flux under the ice varies from $3.54 \mathrm{~W} / \mathrm{m}^{2}\left(h_{0}=1.0 \mathrm{~m}\right)$ to $3.15 \mathrm{~W} / \mathrm{m}^{2}\left(h_{0}=0.3\right.$ $\mathrm{m})$. The standard value was $3.26 \mathrm{~W} / \mathrm{m}^{2}\left(h_{0}=0.5 \mathrm{~m}\right)$. The net freezing rate increases for $h_{0}=1.0 \mathrm{~m}$ by $0.5 \mathrm{~m} / \mathrm{yr}$ and the salinity gradients are accordingly enhanced. For $h_{0}=0.3 \mathrm{~m}$ the opposite is true; the net freezing rate decreases by 0.5 $\mathrm{m} / \mathrm{yr}$. These experiments indicate that $h_{0}$ is an excellent parameter to tune the ice thickness.

3.2.2. The ice strength parameters $P^{*}$ and $C$. An important rheology parameter is $P^{*}$ which characterizes the ice strength (equation (5)). The value used in the standard experiment was $2.75 \times 10^{4} \mathrm{~N} / \mathrm{m}^{2}$. The results of two sensitivity experiments with $P^{*}=5 \times 10^{3} \mathrm{~N} / \mathrm{m}^{2}$ and $P^{*}=$ $10^{5} \mathrm{~N} / \mathrm{m}^{2}$ are displayed in Figure 5 together with the standard run (solid line). The seasonal cycle indicates a small reduction of the ice extent for weaker ice $\left(P^{*}=5 \times 10^{3}\right.$ $\mathrm{N} / \mathrm{m}^{2}$, dashed line) and a slight increase for stronger ice $\left(P^{*}=10^{5} \mathrm{~N} / \mathrm{m}^{2}\right.$, dotted line). The volume, on the other hand, is significantly affected. Figure 5 shows a pronounced increase of $2 \times 10^{3} \mathrm{~km}^{3}$ for weaker ice and a decrease of $10^{3}$ $\mathrm{km}^{3}$ for stronger ice. It is obvious that $P^{*}$ affects the volume far more than the extent, since it decides on the degree to which the ice can be compressed.

The velocity pattern looks similar for all experiments, except for the region near the southwestern coastline, where the velocity for weaker ice is directed more toward the coast, i.e., the ice is more compressed, and the ice thickness is accordingly strongly increased in this region (Figure 6). Stronger ice (larger $P^{*}$ ) has the opposite effect and the ice thickness is accordingly reduced in the southwestern Weddell Sea. The mixed layer depth remains similar, and the average oceanic heat flux under the ice is only slightly modified by $0.2 \mathrm{~W} / \mathrm{m}^{2}$ (larger for $P^{*}=10^{5} \mathrm{~N} / \mathrm{m}^{2}$ and smaller for $P^{*}=5 \times 10^{3} \mathrm{~N} / \mathrm{m}$ ). The net freezing rate and the salinity differ only little for the different experiments.
Another rheology parameter is $C$ which exponentially relates the ice strength to the ice compactness (equation (5)). Two experiments were performed with $C=10$ and $C=30$. The results are similar to the $P^{*}$ experiments. The ice extent was relatively insensitive to this parameter. Increasing $C$ had the same pronounced effect on ice volume as decreasing $P^{*}$, and vice versa (see equation (5)).

3.2.3. The ratio of bulk to shear viscosity e (eccentricity). Variations of the eccentricity, $e$, from 1.5 to 10 have only a minor influence on the model results (Figure 7). Again, the volume seems to be modified more than the extent. Larger $e$ (smaller shear viscosity) allows slip at the coast and therefore smaller volume. The results of an experiment using only a bulk viscosity ( $\eta=0$ or $e \rightarrow \infty)$ are practically identical to the experiment with $e=10$, and, therefore, differ only little from the standard run. Also the geographical distribution of the sea ice and mixed layerpycnocline variables is very close to that of the standard experiment. This indicates that a dynamic-thermodynamic sea ice model using only a bulk viscosity may be sufficient for climate applications. A sea ice model with $\eta=0$ was coupled by Semtner [1987] to an ocean general circulation model (GCM) and applied to the Arctic Basin.

\subsection{Sensitivity to Different Rheologies}

3.3.1. No advection (thermodynamics only). The thermodynamics-only experiment which neglects ice advection
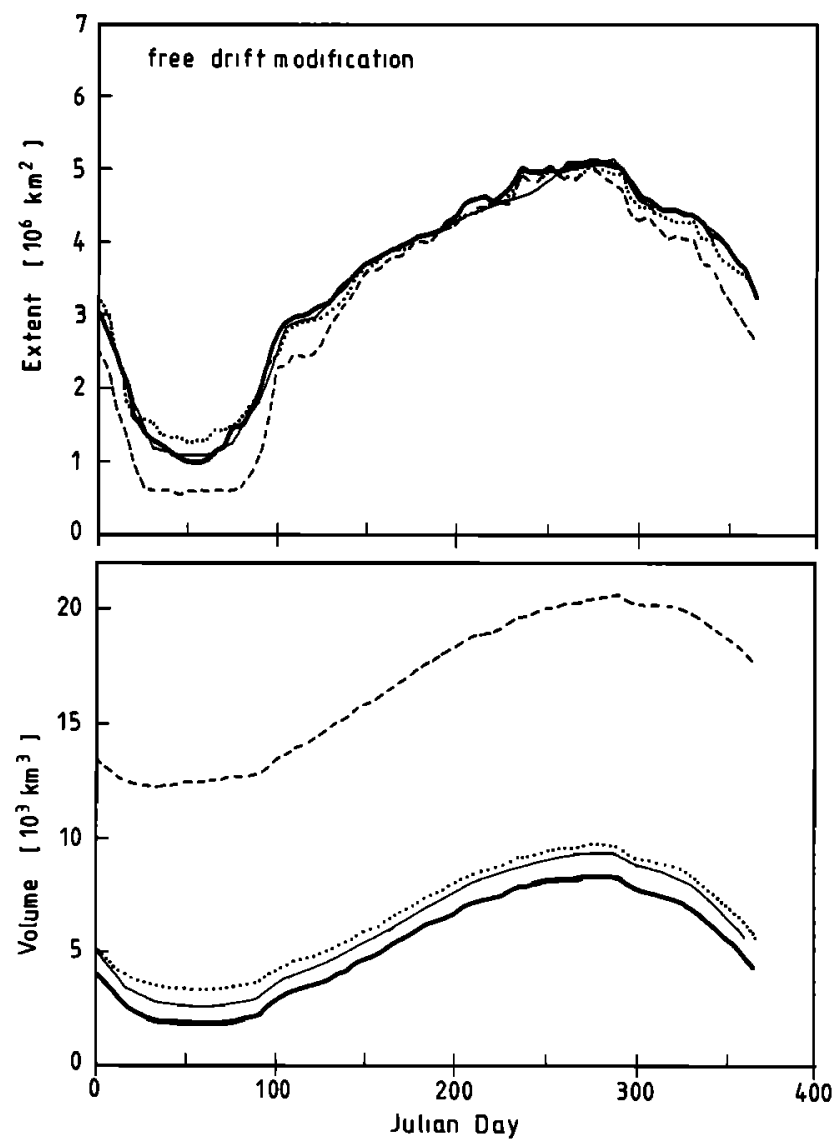

Fig. 9. Seasonal cycle of the integrated ice-covered area (upper panel) and ice volume (lower panel) for the standard run (thick solid lines), the free drift simulation (dashed lines), and the experiments with the first (dotted lines) and second (thin solid lines) modification of the free drift assumption. 

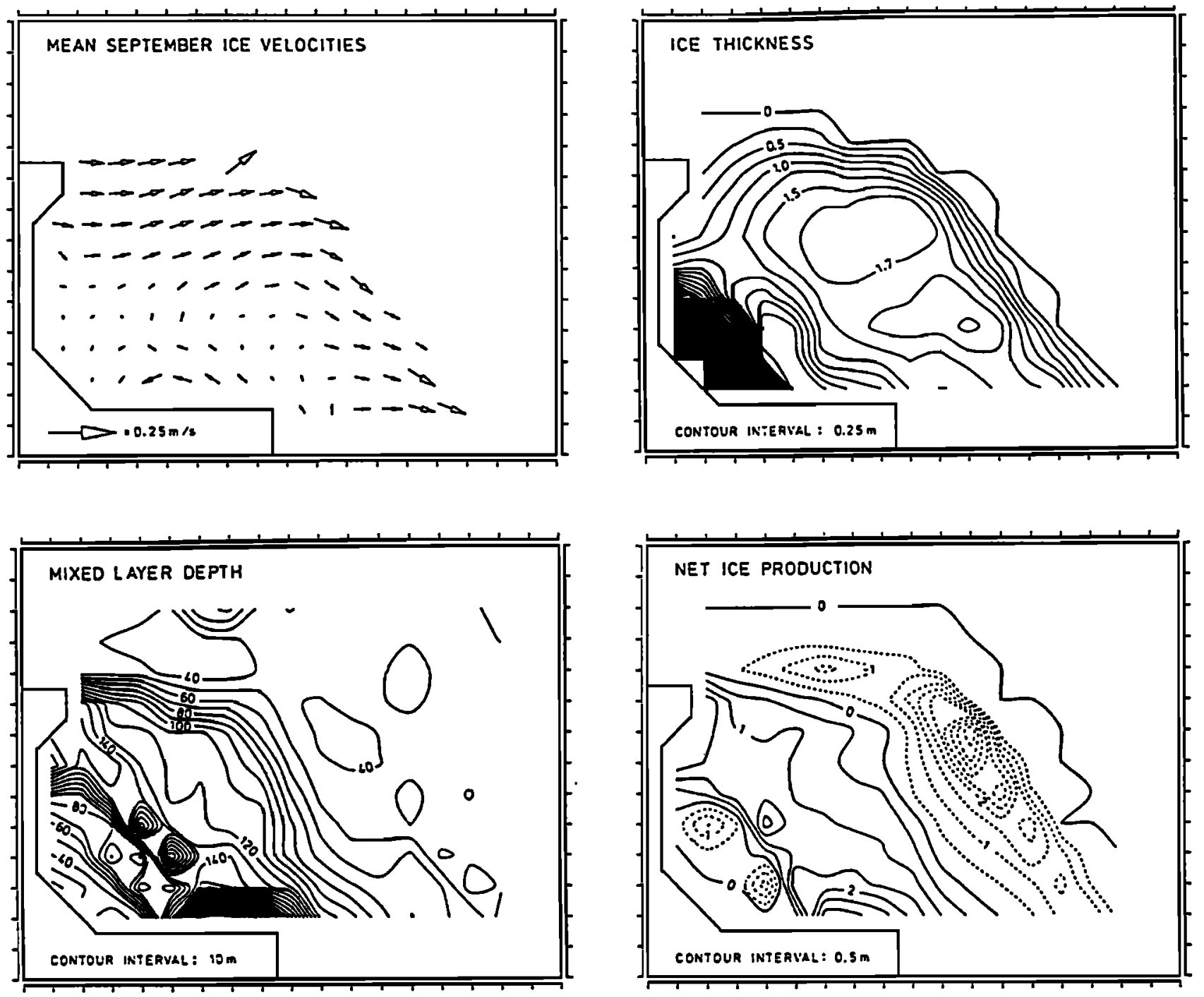

Fig. 10. Simulated mean September sea ice velocities, sea ice thickness and mixed layer depth on October 6, and annual net ice production in the Weddell Sea from the free drift simulation.

and snow cover resulted in a larger ice thickness (Figure 8) compared to the standard run. The ice thickness contours are more or less zonal and reflect the pattern of the surface air temperature. Since the seasonal cycle is strongly reduced (too much ice in summer, see Figure 11 in $\mathrm{LOH}$ ), the ice thickness is relatively high throughout the year, and therefore the freezing rates are smaller than in the standard run. Accordingly the mixed layer depth is drastically reduced in the southern Weddell Sea and reaches a maximum of only 80 m (Figure 8).

3.3.2. Free drift. The seasonal cycles of the ice extent and volume for the free drift experiment $(F=0$ in (1)) are shown in Figure 9 (dashed lines). Although the extent is only slightly different, the ice volume is substantially increased compared to the standard experiment (solid lines).

The reason for this large increase of the total ice volume is that due to the strongly modified ice velocity field (Figure 10) the ice thickness is drastically increased in the southwestern Weddell Sea. At the eastern edge of this thick pack ice there is a small band of thin ice. In this region the mixed layer depth has its largest values. Under the heavy ice cover in the southwestern corner of the grid the mixed layer is rather shallow due to the smaller freezing rates. The pattern of the net freezing rate is strongly modified in this region. The overall amplitude of net freezing and net melting is similar to the standard run.

3.3.3. Free drift modifications. In order to improve the free drift results another experiment was performed in which the sea ice velocity was allowed to follow the free drift as long as the sea ice thickness was less than $2 \mathrm{~m}$. For thicknesses more than $2 \mathrm{~m}$ the ice velocity was set to zero. This is analogous to the treatment of sea ice in the global coupled atmospheric and oceanic GCM by Bryan et al. [1975]. The seasonal cycles of extent and volume are also displayed in Figure 9 (dotted lines) and indicate the drastic improvement by this modification.

Because of this modification the sea ice velocity is zero in the southern half of the model domain (Figure 11) in strong contrast to the standard run, and the sea ice thickness in this region is therefore similar to the thermodynamics-only case (compare Figure 8). As in the thermodynamics-only experiment the mixed layer depth is also strongly reduced in this area, and there is no pronounced net freezing region which we observe in the standard run. 

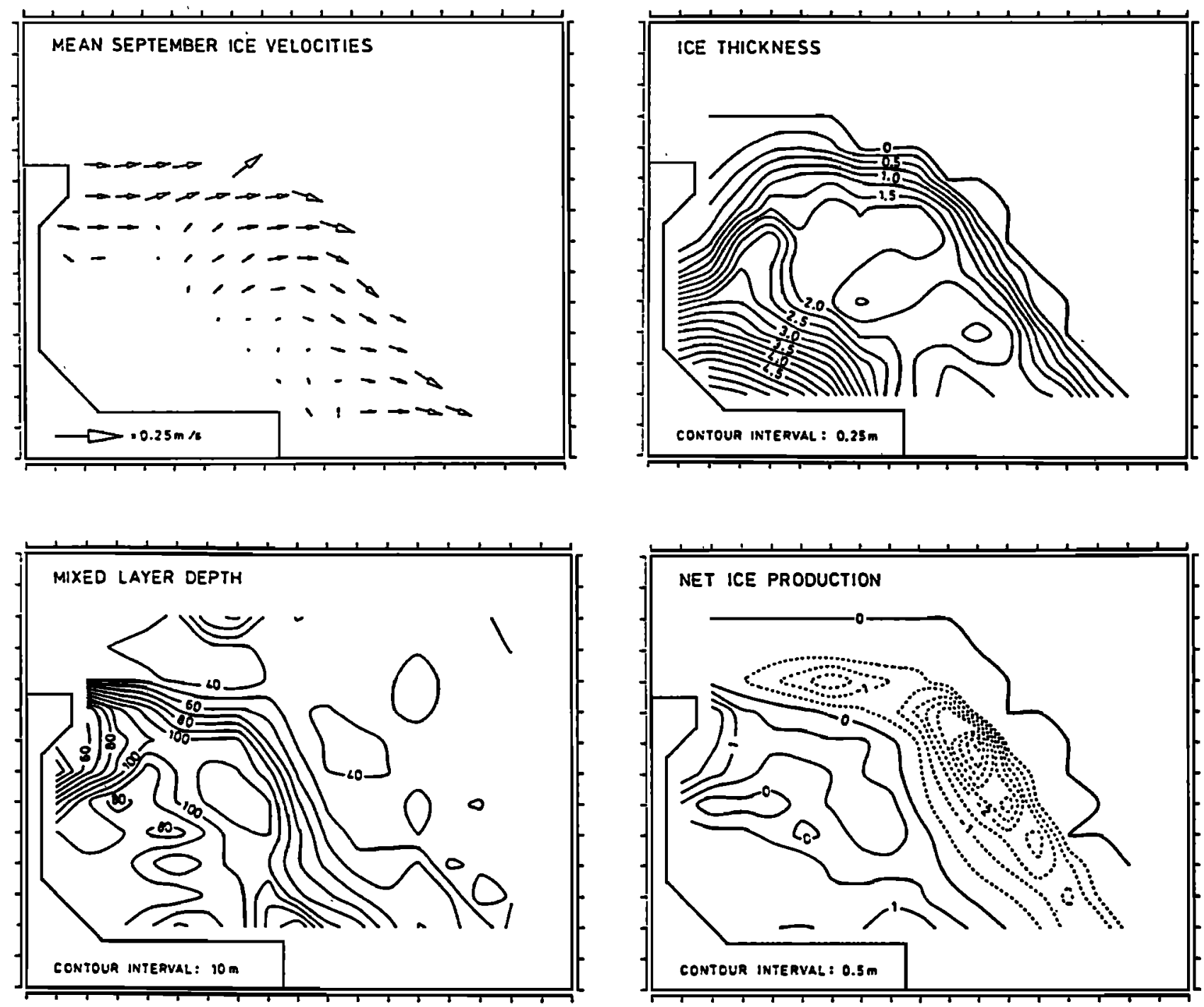

Fig. 11. Simulated mean September sea ice velocities, sea ice thickness and mixed layer depth on October 6, and annual net ice production in the Weddell Sea from the experiment with the first free drift modification (no motion for $\left.h_{t}>2 \mathrm{~m}\right)$.

To further improve the spatial patterns of the sea ice and ocean variables toward the standard experiment, an additional modification was imposed. The sea ice velocity was set to zero only if the sea ice was thicker than $2 \mathrm{~m}$ and if the motion was convergent, i.e., the ice was allowed to follow a divergent free drift motion even if it was thicker than $2 \mathrm{~m}$.

Of all free drift modifications the flow field (Figure 12) for this experiment best agreed with the standard results. The sea ice thickness was improved, and the mixed layer depth and the net freezing rate look very similar to the standard run. The seasonal cycles of extent and volume (Figure 9, thin solid lines) are closer to the standard experiment than the first free drift modification (Figure 9, dotted lines).

In general, the free drift modification, which sets the sea ice velocity to zero if the ice is thicker than $2 \mathrm{~m}$ and if the motion is convergent, yields the best results of all competitive rheologies tested. Nevertheless, the original Hibler rheology shows the most convincing results, but it uses more computer time than the free drift modification.

\section{Conclusions}

The coupled sea ice-ocean model has been shown to be sensitive to changes in both its thermodynamics and dynamics. In particular both the inclusion of a snow layer and changes of the lead closing rate parameter $h_{0}$ reduce the ice thickness significantly, while only slightly modifying the extent. The ice thickness of the snow experiment agrees favorably with observations from the Winter Weddell Sea Experiment [Wadhams et al., 1987].

Changes of the dynamic model parameters had little effect on ice extent. The volume, on the other hand, was modified significantly. Varying the parameters $P^{*}$ and $C$ to increase the ice strength produced smaller ice volume because of stronger resistance of the sea ice to compression. Changes of the ratio of bulk to shear viscosity have a smaller effect on the model results as compared to modifications of the strength parameters. It appears that neglecting the shear 

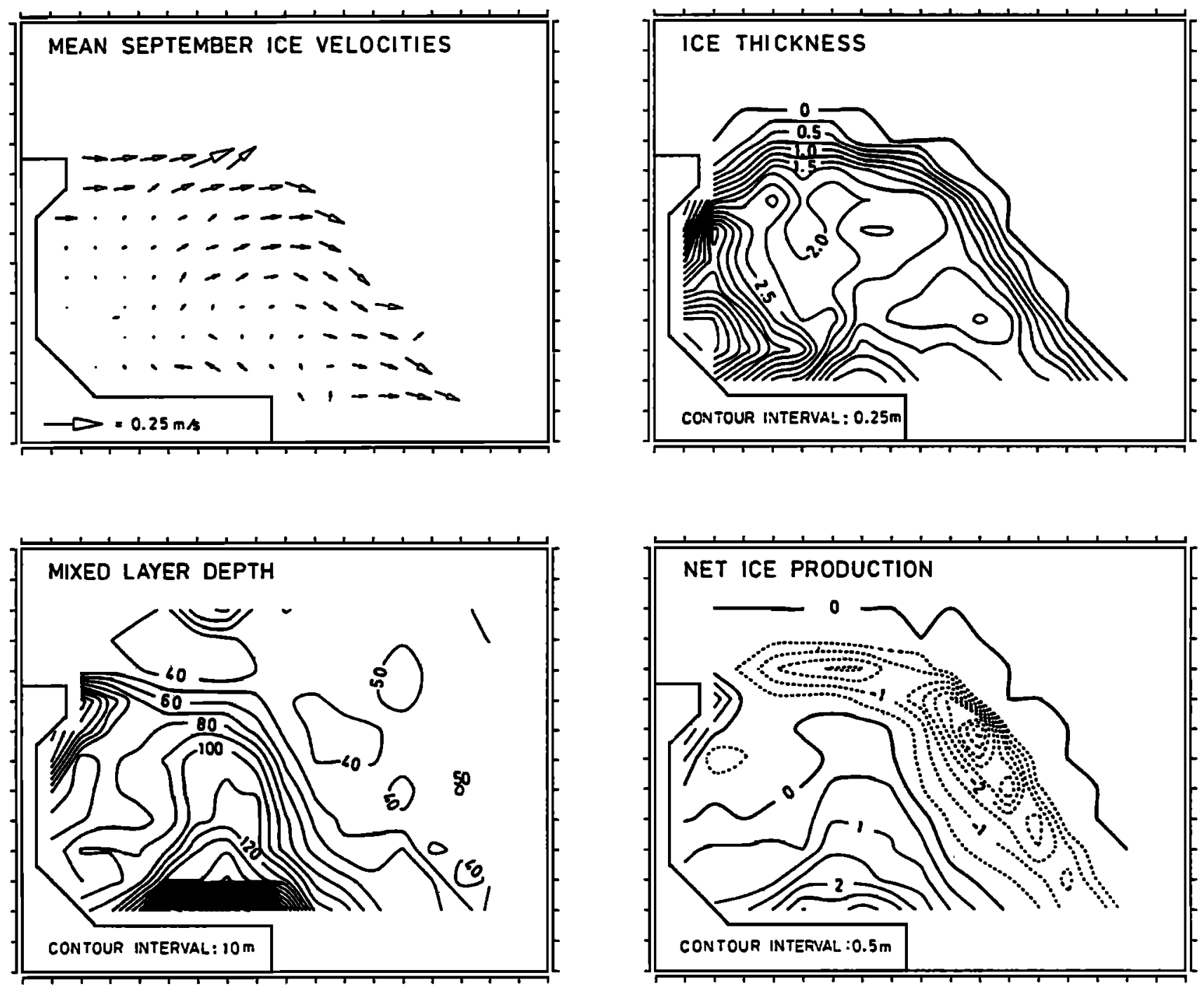

Fig. 12. Simulated mean September sea ice velocities, sea ice thickness and mixed layer depth on October 6, and annual net ice production in the Weddell Sea from the experiment with the second free drift modification (no motion for $h_{i}>2 \mathrm{~m}$ and convergent $\mathrm{u}$ ).

viscosity has little influence on the performance of the ice-mixed layer model.

On the other hand, ice velocities as well as ice thickness are sensitive to these ice rheology parameters (see Figure 6 as an example). Although we do not see any way in the near future to obtain seasonal coverage of ice thicknesses over a large region such as the Weddell Sea, one can expect to obtain such coverage for the ice velocities estimated by tracking features from one satellite synthetic aperture radar (SAR) image to the next. When these data are available one could consider inverse modeling analyses to better determine the ice rheology parameters.

The application of simplified ad hoc rheologies indicates that the free drift simulation can be improved substantially by assuming that the free drift motion stops if it is convergent and if the sea ice thickness exceeds a critical value, which in this paper was taken to be $2 \mathrm{~m}$. The simulation using this simplified advection scheme has a close resemblance to the standard experiment with the viscous-plastic rheology.

The experiments suggest that further tuning (inverse mod- eling) of the model parameters would improve the model performance toward observations of ice extent. But at this stage (without proper ocean circulation models) this does not seem to be appropriate.

Furthermore, the experiments demonstrate that a proper modeling of the sea ice rheology is important, not only to realistically describe the sea ice extent, thickness, and compactness, but also in order to provide the correct forcing fields for the ocean (salt and heat fluxes, net freezing rate), which strongly depend on the nature of the applied dynamic model.

Acknowledgments. The authors would like to thank K. Hasselmann for comments on an earlier version of the paper, and $M$. Grunert for drafting the figures. This work was partly supported by the Max-Planck-Institut für Meteorologie. Additional funding was received from the Office of Naval Research under contract N0001486-K-0751 and from the National Science Foundation under grant DPP-8518747 (W.B.O.). This is contribution 7222 from Woods Hole Oceanographic Institution. 


\section{REFERENCES}

Ackley, S. F., A. J. Gow, K. R. Buck, and K. M. Golden, Sea ice studies in the Weddell Sea aboard USCGS Polar Sea, Antarct.J. U. $S ., 15(5), 84-86,1980$.

Bryan, K., S. Manabe, and R. C. Pacanowski, A global oceanatmosphere climate model, II, The oceanic circulation, J. Phys. Oceanogr., 5, 30-46, 1975.

Campbell, W. J., The wind-driven circulation of ice and water in a polar ocean, J. Geophys. Res., 70, 3279-3301, 1965.

Campbell, W. J., and L. A. Rasmussen, A numerical model for sea ice dynamics incorporating three alternative ice constitutive laws, in Sea Ice: Proceedings of International Conference, Reykjavik, Iceland, pp. 176-187, National Research Council, Reykjavik, 1972.

Felzenbaum, A. I., The theory of the steady drift of ice and the calculation of the long period mean drift in the central part of the Arctic Basin, Probl. Sev. Akad. Nauk. SSSR, 2, 16-46, 1958. (Probl. North, 2, Engl. Transl., 13-44, 1958.)

Hibler, W. D., III, A dynamic thermodynamic sea ice model, $J$. Phys. Oceanogr., 9, 815-846, 1979.

Hibler, W. D., III, Sea ice growth, drift and decay, in Dynamics of Snow and Ice Masses, edited by S. C. Colbeck, pp. 141-209, Academic, San Diego, Calif., 1980a.

Hibler, W. D., III, Modelling a variable thickness sea ice cover, Mon. Weather Rev., 108, 1943-1973, 1980 b.

Hibler, W. D., III, The role of sea ice dynamics in modeling $\mathrm{CO}_{2}$ increases, in Climate Processes and Climate Sensitivity, Geophys. Monogr. Ser., vol. 29, edited by J. E. Hansen and T. Takahashi, pp. 238-253, AGU, Washington, D. C., 1984.

Hibler, W. D., III, Ice dynamics, in The Geophysics of Sea Ice, edited by N. Untersteiner, pp. 577-640, Plenum, New York, 1986.

Hibler, W. D., III, and S. F. Ackley, Numerical simulation of the Weddell Sea pack ice, J. Geophys. Res., 88, 2873-2887, 1983.

Lemke, P., W. B. Owens, and W. D. Hibler, III, A coupled sea ice-mixed layer-pycnocline model for the Weddell Sea, J. Geophys. Res., this issue.

Maykut, G. A., and N. Untersteiner, Some results from a timedependent thermodynamic model of sea ice, J. Geophys. Res., 76, 1550-1575, 1971.

Parkinson, C. L., and W. M. Washington, A large-scale numerical model of sea ice, J. Geophys. Res., 84, 311-337, 1979.

Rothrock, D. A., The mechanical behaviour of pack ice, Ann. Rev. Earth Planet. Sci., 3, 317-342, 1975a.

Rothrock, D. A., The steady drift of an incompressible Arctic ice cover, J. Geophys. Res., 80, 387-397, $1975 b$.

Semtner, A. J., A model of the thermodynamic growth of sea ice in numerical investigations of climate, J. Phys. Oceanogr., 6, 379$389,1976$.

Semtner, A. J., A numerical study of sea ice and ocean circulation in the Arctic, J. Phys. Oceanogr., 17, 1077-1099, 1987.

Wadhams, P., M. A. Lange, and S. F. Ackley, The ice thickness distribution across the Atlantic sector of the Antarctic Ocean in midwinter, J. Geophys. Res., 92, 14,535-14,552, 1987.

Walsh, J. E., W. D. Hibler III, and B. Ross, Numerical simulation of northern hemisphere sea ice variability, 1951-1980, J. Geophys. Res., 90, 4847-4865, 1985.

Washington, W. M., A. J. Semtner, C. Parkinson, and L. Morrison, On the development of a seasonal change sea ice model, J. Phys. Oceanogr., 6, 679-685, 1976.

P. Lemke, Alfred Wegener Institute for Polar and Marine Research, Am Handelshafen 12, D-2850 Bremerhaven, Federal Republic of Germany.

W. B. Owens, Woods Hole Oceanographic Institution, Woods Hole, MA 02543.

(Received June 7, 1989;

accepted July 25,1989 .) 